University of Louisville

ThinkIR: The University of Louisville's Institutional Repository

\title{
Cross-cultural investigation of birth experience : a comparison between Mexico and the United States.
}

Alice J Darling

University of Louisville

Follow this and additional works at: https://ir.library.louisville.edu/honors

Part of the Alternative and Complementary Medicine Commons, and the Social and Cultural Anthropology Commons

\section{Recommended Citation}

Darling, Alice J, "Cross-cultural investigation of birth experience : a comparison between Mexico and the United States." (2017). College of Arts \& Sciences Senior Honors Theses. Paper 135.

http://doi.org/10.18297/honors/135

This Senior Honors Thesis is brought to you for free and open access by the College of Arts \& Sciences at ThinkIR: The University of Louisville's Institutional Repository. It has been accepted for inclusion in College of Arts \& Sciences Senior Honors Theses by an authorized administrator of ThinkIR: The University of Louisville's Institutional Repository. This title appears here courtesy of the author, who has retained all other copyrights. For more information, please contact thinkir@louisville.edu. 


\section{CROSS-CULTURAL INVESTIGATION OF BIRTH EXPERIENCE:}

\section{A COMPARISON BETWEEN MEXICO AND THE UNITED STATES}

By:

Alice Darling

Submitted in Partial Fulfillment of the Requirements

for Graduation summa cum laude

University of Louisville

May 2017 


\section{ACKNOWLEDGEMENTS}

I would like to thank my main thesis advisor, Dr. Christopher Tillquist, for his unwavering support, patience and encouragement, which gave me the confidence to pursue a thesis that fit my passions but was outside of my discipline. I would also like to thank my second reader, Dr. Kandi Walker, for her positivity and insight into the methodology of my project, and Dr. Richard Lewine for taking the time to serve on my committee. There are a number of people who I would like to acknowledge: Dr. Robin Weiss, for being my lifelong doula and inspiring me to love women's health; my non-stop sources of encouragement, Rupika and Danielle; my parents, Doug and Eve, and thesis role model, Emily; and lastly, without the support of the James Graham Brown Foundation and Dr. Joy Hart I would have never pursued my interests to an anthropology field school in Mexico. 


\begin{abstract}
This study investigates the maternal birth experience through a cross-cultural lens. While the field of medical anthropology has researched birth practices of many cultures, few crosscultural studies have been performed and no recent studies have suggested a transition in birthing. Ethnographic interviews with women and practitioners in Yucatán, Mexico and with women in Kentucky, United States allowed for a better understanding of the respective birthing environments. Grounded theory was then employed to develop a birth transition theory explaining changes occurring when society transitions from traditional birth practitioners to allopathic birth practitioners. The themes of knowledge, expectation and power were isolated and further analyzed to outline the transition and explain the impact it has on the maternal birth experience.
\end{abstract}




\section{TABLE OF CONTENTS}

ACKNOWLEDGEMENTS................................................................... II

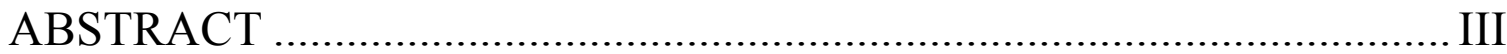

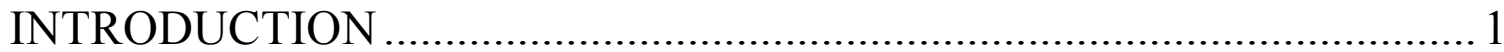

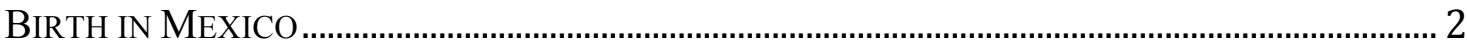

BIRTH IN THE UNITED STATES.............................................................................................. 4

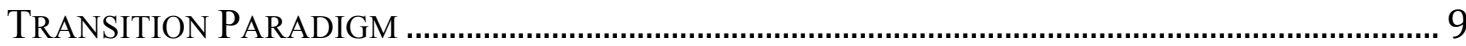

GROUNDED THEORY …………………………………………………………………....10

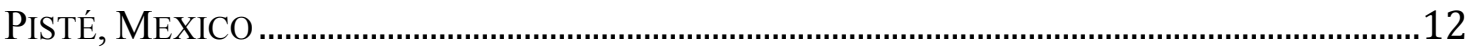

LOUISVILLE, KENTUCKY ................................................................................................13

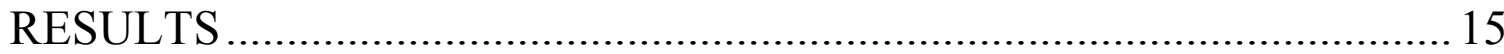

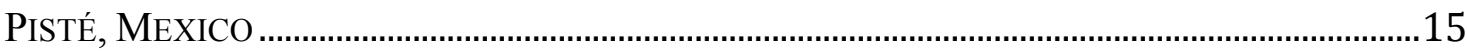

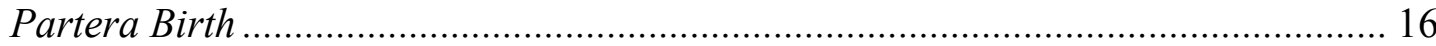

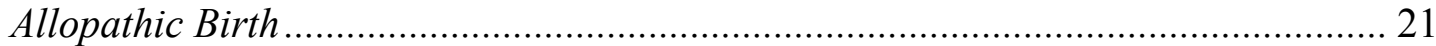

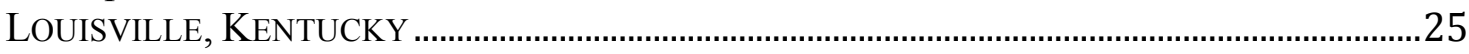

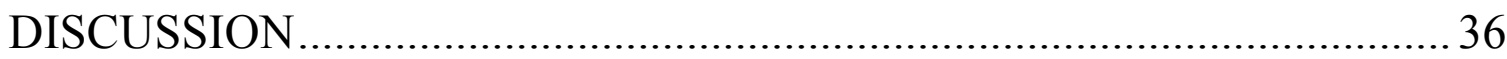

TABLE 1. SUMMARY OF TRANSITION ………………………........................................37

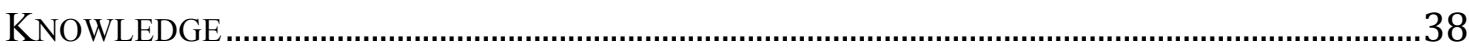

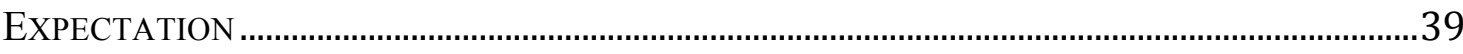

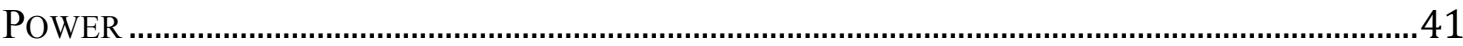

TRANSITION AND TRANSFORMATION …………………….....................................................44

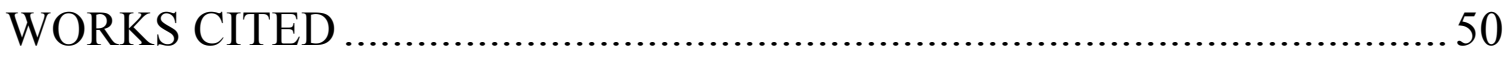

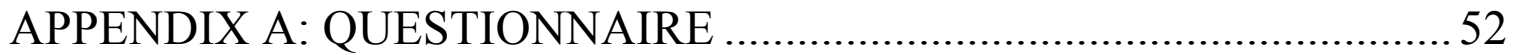

APPENDIX B: INTERVIEW QUESTIONS..........................57

APPENDIX C: STUDY FLYER .....................................58

APPENDIX D: OSEA STATEMENT ON HUMAN SUBJECTS REVIEW/INSTITUTIONAL REVIEW BOARD....................................59 


\section{INTRODUCTION}

This project is a study comparing the maternal experiences of childbirth in Yucatán, México and Kentucky, USA. The goal of the study is to better contextualize health-seeking behaviors of women throughout their pregnancy experience. There are many cultural and societal factors influencing the maternal experience of a pregnancy, and these factors are different in Pisté, Yucatán than in Louisville: these differences are based in different healthcare resources and beliefs related to healthcare. Comparisons will be used to construct a new theory about the impact of transitioning from traditional to allopathic medicine as it relates to the knowledge, expectation, and power of the maternal birthing experience.

This project uses methods and perspectives from the field of medical anthropology to investigate how health-related phenomena are experienced in societies based on different cultures and experiences (Kleinman 1995). While birth seems like an obvious health phenomenon to investigate because it is central to all cultures, birth was not examined through the lens of medical anthropology until the 1978 publication of Birth in Four Cultures by Brigitte Jordan. This book is especially relevant to the work in this thesis because it involved the same region of Mexico. Since Jordan's book, there have been many investigations into the rituals behind biomedical birthing practices, the different models of birth practitioners across the world and the implications of those models; however, fewer studies have focused their work crossculturally to compare different birthing models. Cross-cultural analysis can illuminate the connections between cultural meaning and mainstream practices. Those studies that have been cross-cultural, such as Ways of Knowing About Birth in 3 Cultures (Sargent and Bascope 1996), have focused on static components, like differing use of technology or knowledge between the cultures. For projects investigating the same areas in the Yucatán region-e.g., Pathways of 
Decision Making Among Yucatan Mayan Traditional Birth Attendants (Anderson, et al. 2004)none have occurred since the government began its push to expand its universal healthcare system, Seguro Popular. This thesis focuses on the birth experiences in Kentucky, USA and Yucatán, Mexico with a more recent methodological approach than other medical anthropology investigations.

The methodological approach of this study combines ethnography within a framework of grounded theory. Barney Glaser and Anselm Strauss developed this methodology in the 1960s (Bernard 2006). It is based on an inductive approach to qualitative research and focuses on exploration of phenomena followed by thematic analysis to construct a theory 'grounded' in the results. This theory is applied here to develop an understanding of how the transition from traditional to allopathic birthing care changes the experience of the birth mother with regard to knowledge, expectation and power.

\section{Birth in Mexico}

In rural areas of Yucatán, the traditional Maya beliefs are still practiced for childbirth.

The Maya midwife, or partera, has been the subject of ethnographies by anthropologists such as Brigitte Jordan (1993), Alfonso Villa Rojas and Robert Redfield (1962) and Robbie Davis-Floyd (2001). Many of the birth ethnographies focused on the holistic care of the partera from prenatal sobadas (or massages), to post-partum herbal baths. The traditional practices are rooted in the common Maya cultural knowledge and beliefs, and some understanding of the Maya beliefs about illness provide a as context for understanding the traditional birth experience.

Chan Kom: A Maya Village, written by Redfield and Villa Rojas (1962), describes the Maya illness belief system as based on more supernatural and holistic ideals than biomedicine. This belief system will be referred to as the traditional model of care throughout this paper. The 
traditional beliefs assign a "hot" or "cold" value to many actions, foods, or even people, and dictate the diets and cures needed for particular illnesses. According to Jillian Gezelle in $Q^{\prime} e q c h i^{\prime}$ Maya Reproductive Ethnomedicine, "this classification does not refer to the actual thermal state of the food, plant or person. Rather this is more of a culturally attributed symbolic categorization, association and value." (2015:18) For example, honey is a hot food and pork is a cold food. In childbirth, cold is seen as harmful. After birth, a woman is to avoid "cold" foods and stay indoors to avoid a "cold" wind. In general, the expecting mother in the traditional model is an active and knowing participant who understands the background of the childbirth practices because they are part of her culture. The above explanation is only a brief summary of the model and there are many other components to traditional Maya health beliefs, but in general, it places health knowledge as holistically encompassing psychological and social implications of body states. Each person has folk knowledge of medicinal treatments, and the understanding behind the practices of the partera is common knowledge to those in the culture.

The area of Mexico investigated in this study overlaps with the towns included in the ethnographies done by Jordan (1978), Villa Rojas and Redfield (1962) and Davis-Floyd (2001), but provides a more current account. Since 2009, there has been a national campaign for enrollment in the Mexican universal healthcare system, Seguro Popular. This push increased members by 20 million in just four years and led to the construction of town clinics in many areas that never had access to Western medical care. Historically, the only birthing option was the partera in one's town or towns nearby but now, in most cases, the options include an obstetrician-attended hospital birth. The free biomedical care offered at these clinics made the obstetrician model of birthing available to women in the Yucatán and has begun to replace the traditional birthing practices. In Birth in Four Cultures, Jordan mentions the symbolic value of 
biomedicine as a marker of Westernization. The symbolic value may explain the "unquestioned" status of the newly implemented biomedical model and "blanket condemnation of traditional practitioners" by biomedicine in more urban areas of the Yucatán (1993:131). Seguro Popular is the universal healthcare provided by the Mexican government and it is essentially free for those who sign up. In general, I will portray the maternal birth perspective of using Seguro Popular because that is the non-traditional option available to all pregnant women.

\section{Birth in the United States}

In the United States, the biomedical model of medicine has for decades been hegemonic, that is, the allopathic birthing practices are not only the most common but are also supported by mainstream media, laws about birthing, and government programs. Allopathic medicine as we know it today was not always present in the United States. Understanding the transition that occurred in the United States towards allopathic medicine is an important component to constructing a new transition theory. The development of medical technology for birth pain relief caused a shift from a "social childbirth philosophy" to a "medical illness model" of birth in the 1900's (McCool and Simeone 2002). The medical illness model emphasizes the tools of medical intervention and technological monitoring in the pregnancy and labor process. The medical illness model is centered on hospitals with obstetricians as the birth practitioners. To encourage hospital-birthing practices and the use of technological interventions, the practices of traditional midwives were devalued (McCool and Simeone 2002) and in some places, like Kentucky, licensing of midwives was suspended. In addition to devaluing the traditional practices, the transition to the medical illness model also included an overvaluing and over-application of novel biomedical resources. The emphasis on using medical intervention to lessen childbirth pain in the early 1900's even went as far as the Twilight Sleep phenomenon which employed drugs to 
create a semiconscious birthing woman who lost psychological inhibitions during labor but would not remember the birthing pain (Wolf 2009). Although the Twilight Sleep birth is no longer endorsed today, the medicalization of birth is still the norm in American birth culture.

In addition to increased use of Cesarean sections, which can provide healthy outcomes in complicated birth situations, there is also a high rate of interventions such as medical induction of labor and use of epidural pain medication for vaginal births. As described in Lydia Zacher Dixon's article Obstetrics in a Time of Violence, the over-medicalization of birth and strong value of biomedicine, has led to a form of violence through procedures like unauthorized episiotomies and "the manual revision of the uterine cavity" (Zacher Dixon 2015:445). While these practices are certainly influential to understanding the rejection of the obstetrician model of birthing by some women, these practices, often termed obstetric violence, will not be a component explored in this thesis independently of birth stories expressed by research subjects.

In thinking of the biomedical culture, investigated in Janelle Taylor's article Confronting 'Culture' in Medicine's 'Culture of No Culture,' it is important to understand how technological advances and the medicalization of birthing have changed the experience of birthing itself (Taylor 2003). Biomedicine is often seen as a-cultural, yet it involves its own rituals and beliefs. In the context of childbirth, the development of technology to monitor health status contributes to the culture of micromanagement in biomedicine that has led to the medicalization of birth and the progression away from the view of birth being a social, collaborative, and natural process. Biomedicine places value and authority in the hands of physicians and in turn devalues other cultural birth practices. 'Allopathic' will be used to describe this biomedical model of healthcare. Rediscovering the Social Model of Childbirth, by Sheila Kitzinger, highlights the ways American treatment and perception of childbirth has been transformed, and explains how the 
medicalization of birth changed the experience from a celebratory accomplishment to a medical drama (Kitzinger 2012).

Not only has the shift to a medical illness model been apparent in the increase of medical interventions, but it is also manifested in childbirth discourse. With the extensive selection process followed by years of training that physicians must pass through, they are often treated as all-knowing. The inaccessibility of allopathic knowledge makes disease treatment a literacy issue for the general population, and allows the practitioners to hold authoritative knowledge and power over the patient. This dynamic greatly impacts the obstetrician-woman relationship and accepted practices in a medicalized setting.

The practitioner's power over the patient is now being re-balanced by the consumer model of healthcare. In this model patients are able to shop around for the healthcare they want instead of being restricted to a particular physician (DuPré 2014). Because of this model, the physician bedside manner has become more important in patient care. The patient is able to demand a level of respect from a physician because the patient's ability to switch physicians gives them some power in the relationship. While this model is generally true for obstetricians, once in labor, the woman practically has no power to leave and switch physicians because emergent care is needed. Thus, in the context of delivery, bedside manner is not as pressured by the consumer power of the woman who is now immobile and must accept the practitioner present in that moment.

While mainstream birth in America is medicalized, there are other common options depending on region. In Women's Childbirth Preferences and Practices in the US, Miller identifies homebirth with a midwife, hospital birth, and home birth with no professional as the main options in America (Miller and Shriver 2012). Birthing centers with midwives are a middle 
ground between a homebirth and hospital birth in some areas, however there are not currently any in the Louisville region. In addition, Louisville has one hospital with Certified Nurse Midwives practicing; however, Certified Professional Midwives may not practice legally in Kentucky.

Unlike the parteras in the Yucatán, the midwifery in the United States has no clear root in indigenous beliefs. The Certified Nurse Midwives and Certified Professional Midwives are two distinct branches of midwifery that represent the rebirth of midwifery in the U.S. Midwives split in several directions demonstrating the development of the consumer model in the creation of practitioners to fit the needs of the consumer. There seems to be a gradient to the variations of midwifery in the U.S. but the Certified Nurse Midwives and Certified Professional Midwives make up the two main categories of midwives and represent two different models of care (Dawley 2003). There are philosophical differences in these two types of midwives, which are rooted in the ideas about the training process and certification necessary and stem all the way to the types of interventions each is comfortable with providing during labor (Davis-Floyd and Johnson 2006). The main difference between the two is that Certified Nurse Midwives have a nursing degree and Certified Professional Midwives do not.

In Kentucky, there has been a rich history of midwifery landmarked by the Frontier Nursing University. The Frontier Nursing University is a midwifery school that was founded in 1939 and contributed to the development of nurse-midwifery in order to increase care for women in rural eastern Kentucky. This school is currently ranked by the U.S. News and World Report among top 50 of graduate schools of Nurse-Midwifery; however, midwifery in Kentucky still faces huge opposition today. While Certified Nurse-Midwives are able to practice in hospitals in Kentucky, professional midwives — lacking a nursing credential—are not allowed to practice 
without a license. Kentucky has not issued any licenses since 1975. Although planned homebirths attended by unlicensed midwives do occur in Louisville, concomitant care with an $\mathrm{OB} / \mathrm{GYN}$ is not permitted and the only legal midwives are Certified Nurse Midwives who practice at University Hospital or across the river at Clark Memorial Hospital, in Indiana. Conflicts surrounding midwifery have been internal, between these two groups, as well as external with pressure from obstetricians and physicians to avoid the threat of midwifery to their monopolization of birth (Savage 2007).

Based on the consumer model of healthcare, each consumer has individualized wants and needs so, depending on culture, socioeconomic status, access, interpretation and values, each woman may experience a different environment each time they give birth. In some instances, birth is viewed as an accomplishment and actualization of womanhood, for others it is only a clinical procedure to be endured. As discussed in many anthropological articles about childbirth, the environment of a woman's birth is also determined by her expectations about what constitutes a good birth (Fleuriet and Sunil 2016; Jordan and Davis-Floyd 1993; Kitzinger 2012). Conceptually, a psychosocial framework is often undervalued in obstetrician-based care yet has been shown to influence allopathic outcomes. In order to understand the needs of women to create a positive birthing mindset, the expectations and reactions of women will be explored. The three themes of knowledge, expectation, and power will be applied to the responses of women in Mexico and the United States to ask how cultural background, individual expectations and birthing methods influence the maternal birth experience. Furthermore, the thesis will focus on defining the location of Mexico and the United States in the transition between holistic and allopathic birthing care and how that manifests in the maternal experience of birth. 


\section{Transition Paradigm}

In the traditional model of healthcare, the knowledge of healing practices is based in the local culture. There is a component of belief that is relevant to the practices and those beliefs are passed on through families. Everyone in the culture is aware of the beliefs, and these beliefs guide the health practices. There is an expectation of collaboration in the healing event because the traditional medicine is more holistic and the practitioner is a respected member of the community. Because the patient has the same beliefs and awareness of the healing practices, the power dynamic between the practitioner and the patient is more equitable. The family of the patient also holds power in the decision-making, and family elders may be able to influence the healing practices and provide their advice along with the practitioners.

In contrast, the allopathic model eliminates the element of belief from the healing practices. The knowledge of the practices comes solely from the practitioner's interpretation of symptoms based on years of complex training. The family knowledge is often discounted and the only other opinions considered in the healing process are those of other allopathic practitioners. The expectation of the healing encounter is that the allopathic practitioner will offer a tangible solution to the symptom. Because of the inaccessibility of professional healing knowledge, the allopathic practitioner holds all of the power in the decision-making. The power of the patient is only in whether or not to receive treatment. In some allopathic models, the patient is able to claim more power by creating a consumer model in which the patient can shop around for a different practitioner. To some extend, the consumer model holds the practitioners accountable to a specific doctor-patient relationship.

As cultures Westernize and the traditional model of healthcare transitions to the allopathic, (Jordan and Davis-Floyd 1993) shared cultural knowledge is devalued. The expected 
collaborative environment of the healing process is erased, as the patient no longer has valuable knowledge of the healing practices to contribute. The patient loses much of their power in the relationship because they begin to highly value the technological advances over their cultural beliefs. Without knowledge or power to contribute to the healing process the expectation of the encounter has not developed and patients may reject the use of allopathic medicine all together or embrace it without a standard of care.

In the context of birthing care, the transition from traditional to allopathic medicine can greatly impact the maternal birth experience with regard to knowledge, expectation and power. In the applied sense, understanding this transition will allow construction of more effective birthing practices by better accommodating the deficits created from practitioners with an allopathic background treating patients with a background of traditional healing practices.

\section{METHODS}

\section{Grounded Theory}

Grounded theory methodology shaped the components for this research as a whole. As described in H. Russell Bernard's Research Methods in Anthropology (2006), the steps to grounded theory are:

(1) Produce transcripts of interviews and read through a small sample of text. (2) Identify potential analytic categories - that is, potential themes-that arise. (3) As the categories emerge, pull all the data from those categories together and compare them.

(4) Think about how categories are linked together. (5) Use the relations among categories to build theoretical models, constantly checking the models against the data-particularly against negative cases. (6) Present the results of the analysis using 
exemplars, that is quotes from interviews that illuminate the theory. (463)

This methodology has been used for many ethnographic studies and, with regard to the current study, is justified because of the exploratory nature of this thesis. The lack of recent anthropological investigation comparing birthing methods in Mexico and the United Statescombined with the lack of anthropological investigation into any cultural birth transition as a base for this research — means that understanding the current birth environment is a needed first step.

An ethnographic approach was taken for data collection. Informal interviews, participant observation and exploration of birth as a general theme was done in Mexico and the U.S. This approach allowed me to accumulate background knowledge to better form questions in interviews and understand responses given by informants. More formally, an initial questionnaire and interviews took place in both Pisté and Louisville. Opportunistic sampling was used to contact mothers to participate. The questionnaire was used to gather common demographic information about research subjects while the interviews allowed a more in-depth understanding of the birth experiences of women. The informal and semi-structured interview formats reduce the impact of leading questions in structured interviews and allow for the collection of a broader base of information.

An inductive approach was taken for this thesis in order to isolate and further examine the analytic categories of knowledge, expectation, and power. Case studies and exemplars were used to describe the results of the study. Because of the method used to identify potential participants, there is no claim that the women sampled are proportionately representative of the entire population; thus, no statistical models are considered. Thematic analysis of ethnographic interview data using the grounded theory methodology is standard. 


\section{Pisté, Mexico}

The first phase of research took place in Pisté, Mexico, a town with a population of about 4,500. Pisté is the town most closely located to the archeological site of Chichén Itzá but, because of highway rerouting, is no longer the associated tourist destination. This phase of research took place in June-July 2016 under the guidance of faculty at the Open School of Ethnography and Anthropology (OSEA), an anthropology field school associated with Indiana University, Bloomington. All research was overseen by the Director of OSEA, Dr. Quetzil Castañeda, in accordance with the Indiana University statement on the exemption of student research from the Institutional Review Board ${ }^{1}$. The first stage of the project included gathering background information through interviews with local residents, and public and private physicians. All interviews in Mexico were conducted in Spanish. I interviewed four allopathic practitioners: one nurse, two government-run clinic doctors and a private doctor. I chose these practitioners because they were in the main clinics in Pisté and Kaua, a smaller town outside of Pisté. In addition to allopathic practitioners, I interviewed a sobadora. A sobadora is a traditional healer who performs prenatal massages as well as massages for general muscle injuries and spiritual illness. I identified these informants through their medical practices and through recommendations from town members. I used opportunistic sampling to find informants to interview. I was able to interview informants based on home-stay families of classmates, by approaching strangers, and through friends of a birth counselor.

The research subjects interviewed in Pisté, México had a variety of backgrounds. Many of my interviews lasted over an hour and were semi-structured, following a set of interview questions that led to further unstructured conversation. In order to familiarize myself with the culture and partera practices in Mexico, the interviews were focused on the actual practitioner

\footnotetext{
${ }^{1}$ Refer to Appendix D.
} 
practices and cultural beliefs. I attempted to ask open-ended questions about topics and let the women lead the conversation so that I could determine what they deemed important, based on what they brought up instead of by asking leading questions.

I gained valuable data from a participant observation perspective in a prenatal check up at a major hospital. The methods for this experience involved observation and a post-appointment interview to gain the opinions and reactions of the patient. Because this portion of the project was not culturally familiar to me, it was helpful to attend an appointment for background information and to learn more about the doctor-patient customs in Mexico.

According to Russell Bernard in Research Methods in Anthropology, "once a model starts to take place, start shopping for negative cases—ones that don't fit the pattern.” (2006:469) Most of my interviews were in Pisté and I wanted to gauge the cultural differences between that town and a more rural town with less allopathic influence. In order to search for 'negative cases,' I interviewed women from the poorer and richer parts of town and ventured to Dzitas and Kaua (nearby towns) to hear a more rural perspective. I created a brief questionnaire focused on healing beliefs and trust in allopathic medicine versus traditional medicine practitioners in order to search for negative cases. I administered the questionnaire verbally to 16 women.

\section{Louisville, Kentucky}

The second phase of research was conducted in Louisville, Kentucky, with a much larger city of a population of $1,269,702$. One parallel to Pisté is that the field of midwifery is also facing challenges in Louisville. Whereas in Pisté, the midwives are dying out and becoming less common, in Louisville they are less common because of legislation against Certified Professional Midwife licensing. There is no birthing center with professional midwives just as there were no Mexican government-trained midwives in Pisté or surrounding towns. In 
Louisville, despite the legal complications associated with practicing midwifery, there is a rich community of maternity practitioners. The birthing practitioners available in Louisville include childbirth educators, doulas, professional midwives, hospital midwives and obstetricians. The variety of practitioners reflects the allopathic consumer model.

University of Louisville Institutional Review Board approval was obtained for the portion of the project performed in Louisville (16.0971). An initial questionnaire that was distributed online was used to make contact with mothers. The online questionnaire allowed me to gather uniform information from each research subject. I was able to assess demographic and socioeconomic differences in responses and preliminarily categorize women to give me analytical leads, which I pursued during the more in-depth interviews. The initial questionnaire collected information from participants such as the types of practitioners employed for their birth, the setting of their birth, any medical interventions used for the birth and factors that were most important to them in planning the birth. After the questionnaire, women were able to schedule an interview through contact information provided at the end of the questionnaire. Semi-structured interviews were then conducted with women who emailed the research email account.

The interviews were conducted at local libraries and coffee shops. All of the interviews involved structured questions including the stories of the birth experience for each pregnancy, the influences that impacted the woman's choice of practitioner, and the positive and negative aspects as experienced by the mother, in addition to unstructured questions investigating themes that came up. There were 15 interviews conducted which lasted from 35 minutes to one hour. All of the interviews were recorded and an informed consent document was procured. Interviews were conducted with women who had each type of birth: vaginal birth in a hospital, Cesarean 
section in a hospital, homebirth, and midwife-assisted birth in a hospital.

Mirroring methods in Pisté, in Louisville I used my social network to disseminate the initial questionnaire. I also asked a birthing class instructor to distribute the link through social media groups that were birthing focused but not specialized to natural or home birthing. This method mirrored the technique in Pisté of using a woman who taught a birth class for advice to facilitate contacting potential informants. Flyers ${ }^{2}$ for the online questionnaire were posted on social media, in the University of Louisville School of Nursing, and in a baby store as another means to recruit research subjects outside of personal social networks.

\section{RESULTS}

The results of the fieldwork of this study will be presented as they relate to the knowledge, expectation, and power dynamics of the maternal birth experience. These components describe the ways the transition from traditional medicine to allopathic medicine changes the maternal birth experience. The location of Mexico and the United States along the transition will also be discussed.

\section{Pisté, Mexico}

Fieldwork in Pisté assisted in a greater understanding of cultural background information and context in order to better formulate questions and understand the maternal birth perspective in this region. I administered the questionnaire to 16 women and I interviewed seven women ranging in age from 23 to 65 years old with an average age of 44 . While not all experiences can be generalized, two distinct maternal birth experiences emerge from the data. It was clear that the women who went to an obstetrician had experiences more closely resembling those in the U.S.

\footnotetext{
${ }^{2}$ Refer to Appendix C.
} 
than the Mexican women who had a partera-assisted birth. Although both allopathic experiences had similar components, it is still necessary to present each individually due to the recent introduction of allopathic medicine in Mexico, as compared to the United States, causing different maternal birth experiences. All quotes from Mexico have been translated into English based on transcriptions of interview recordings.

\section{Partera Birth}

Knowledge

In the traditional model of childbirth, cultural knowledge is valued to guide the practices. In Pisté, the partera is the trusted conduit of that knowledge in the birthing setting, however the mother also has cultural literacy to understand and believe in the practices of the partera. One display of that literacy is the detailed birth stories and treatments relayed by mothers. Many of the women I interviewed instructed me about the different treatments parteras use in childbirth. Isabella said the partera instructs a woman to eat an onion "to help open the body and allow the baby slip out more easily." She referenced the slippery skin of the onion, as well as how its layers unfold, as the explanation for its use. In order to speed up labor, Isabella said the partera will give the pregnant woman a drink consisting of honey and boiled Pixoy, which is a tree bark with medicinal properties but a bitter taste.

While the partera is relied upon to guide the woman through labor as well as take care of the woman after birth, much of the knowledge in regards to recipes for treatments was widely known by the older generation of women. Luisa described the postpartum rituals that took place.

For example, the $8^{\text {th }}$ day after birth was culturally significant. On the $8^{\text {th }}$ day, the partera returns to the house of the woman to 'amarrar' the body. According to Luisa, this means The partera starts with a sheet and wraps it around the head. [Q: Very tightly?] Pretty tight, she tightens it around your head and then she ties it here and continues down the 
body until the point of your toes. Then, after that, she wraps your belly. Then you can leave the room, you and your baby can leave and the partera has finished her work. [Q: Why does she do that?] Because, according to the partera, the woman is weak and she can't be exposed to the wind with the rain in the afternoon because it is cold.

Many women don't do this and sometimes they get sick because, according to my mom and the partera, when you lose a lot of blood in having the baby you are weak, so if you don't avoid the cold wind it can give you a fever or diarrhea" [Q: What do you do if you get sick from the wind?] Well, the partera comes back and she will prepare other herbs to give you to drink to get rid of the sickness. The same partera can cure you. Historically, the parteras were really good because they know, they know what herbs are special for these cases. This happened to me once.

The partera prepares a bath for you on the third day. She boils herbs and prepares the water for you to bathe in. This is the third day after the birth and you shouldn't get up or leave for anything. This is because the partera says the effect of the herbs is hot so you can't be exposed to the cold air because it can make you sick. I was bathing when a strong wind came and the partera covered me but the wind got to me because my house wasn't like this, it was made of wood and the wind got through. So I had a fever after that. My bones hurt everywhere and she had to prepare a stronger bath for me, with stronger herbs. I lay in the hammock and under the hammock she put a tub with the herbs and the vapor of these herbs came up to my body. When I started to sweat, I sweat a lot and then after, when the water was cold, I dried off well and put my clothes on and the fever didn't return.

According to traditional knowledge, after this day the baby and woman are less vulnerable to "cold" winds. In this example, it is demonstrated how the "hot" and "cold" concepts of illness in Maya tradition are tied to the partera practices. This display of detailed knowledge, in regards to the birthing practices, shows how in the traditional holistic model of birth, the mother is knowledgeable because her cultural knowledge is valued.

My interview with Camila, the sobadora, helped me understand how the knowledge of the traditional birthing practices is passed along to younger generations. 
The person has to be born who likes it, not everyone has patience to sobar. [Q: Was it hard to learn?] If you want to learn then it's easy but if someone doesn't like it, then they can't learn it. You want them to like it so they learn it quickly.

Camila said neither of her children are interested in learning the practice.

\section{Expectation}

Because of the cultural knowledge serving as the base of the partera practices, there is an expectation for the birth to unfold a certain way. Birth is more of a family event and life as usual goes on outside of the room with the mother laboring. All of the mothers I spoke to who used a partera had their babies in their home with their family around.

In general, the maternal birth experience with a partera is dictated by traditional practices with roots in the Maya illness belief system. One example of such a practice is the prenatal massage or sobada. In an interview with Camila the sobadora, a masseuse who does prenatal massages but does not deliver babies, I was shown the different ways to sobar and the instances in which it is used as a treatment. In addition to its use in comforting the baby, the sobada can help locate and reposition the cirro or tipte (an organ believed to exist beneath the belly button of spiritual significance which can fall "out of place" and cause illness). The pregnant woman's first interaction with the partera is in prenatal appointments where the baby is massaged, repositioned and named a gender. One woman said the partera "massaged my abdomen and said all of the bad would go away. Afterwards I felt like new."

With a partera birth practitioner, there is continuity in the birth experience because one person is providing care throughout the prenatal appointments and birth. The partera was often a familiar community member, and many times women said their mothers or mother-in-laws used the same one. Not only is the partera present in prenatal appointments but also in after-care of 
the mother and is often used for future births. According to Luisa:

The partera will be with you for 7 days after the birth, they take more care of the moms. After 40 days, the woman can leave the house to go to town with no worry. [Q: Was it hard to wait all those days?] Well since it is a custom you expect it to happen and if you take care of yourself then you won't get sick when you go out. [Q: Did you do this after you got home from the hospital?] No, with the doctor no.

The women who use parteras have cultural expectations about traditional birth practices and they have beliefs tied to those practices, yet, when placed in a new setting the traditional practices seem not to apply and any expectations from the partera are just abandoned. Although none of the women I interviewed had doctor-patient relationship expectations as is common in the United States, the women who had more experience with allopathic medicine, did display more awareness about allopathic norms. For example, Sofia, who had used allopathic medicine through each of the different insurance options in Mexico, provided insight into each of the insurance systems as well as the stereotypes of each, the historical development of each in the nearest city, and the instances in which you should rely on one or the other.

Power

The power dynamic in the partera birth experience allowed the mother to be active and play a role in the birth but still gave the partera cultural value. Although the treatments were common knowledge, the parteras remained important for the prenatal massages called sobadas and the actual delivery of the baby. While all of the detailed birth stories using a partera followed the same basic outline, there is also some individual variation in how parteras practice. Small details such as whether or not the partera stays in the house with the mom and what specific herbs she uses differed somewhat between interviews. This variability may be described by the differences in town practices or generational experience, however it demonstrates that the 
parteras have a cultural power to control their specific practices within the Maya traditional medicine framework.

In the birthing experience the mother-in-law is also another agent of power that was mentioned. Luisa specifically said:

My older daughter used a partera, but my younger daughter used a doctor. [Q: Why?] Well her mother-in-law told her "no, better with a doctor." My other daughter's mother-in-law was also like us, so she believed in the partera and that's why she used the partera. [Q: Were you there for your daughter's births?] No, because she was with her mother-in-law, it would have been nice but her mother-in-law said "no" she said she would be there. [Q: Did you help her find the partera?] No, her mother-in-law oversaw it all. Her mother-in-law knew the partera because she doesn't live with me she lives with her mother-in-law.

The cultural power distribution in the family is seen to have an impact on the maternal birth experience. With the traditional model, the elder woman in the house is able to take some control over the birth, which demonstrates value in knowledge of the birth experience regardless of a practitioner title. When Luisa spoke about the practices of the partera she almost always said "according to my mom and the partera" meaning the birth was more collaborative between the knowledgeable women present. During labor, the partera was described to have a firm but not restrictive role. Women were free to birth in a variety of positions including in hammocks, on birthing stools and squatting. Camila said the women could choose whichever position was most comfortable and Valeria said she even gave birth in a plastic lawn chair.

Although they are less prevalent now, the partera cultural power has a lasting impact as described by a doctor at the health center. In Kaua, a smaller town outside of Pisté, allopathic medicine is less developed. The doctor running the clinic there said he often would ask the partera for advice. He said having the support of the older women in the town gave him better 
rapport. He admitted that the presence of parteras was more traditional than tangible and he spoke about them in an outdated way. Luisa also spoke about the partera in this way she said "historically the parteras were very, very, good because they know the herbs for special cases; no one believes in them anymore." This explanation shows a decline in the partera acting power, while still maintaining strong cultural significance.

\section{Allopathic Birth}

Knowledge

In speaking with the younger generations of women who almost all used obstetricians, there seemed to be a lot of misinformation. I especially noticed women reporting a variety of inaccuracies about rules surrounding Cesarean sections. While the partera practices are more culturally understood, the allopathic medical knowledge is less accessible to the mothers so they viewed the doctors as "all-knowing" within the allopathic model. As part of the interviews with women who had Cesarean sections, I asked about implications of having a surgical delivery. Many women gave different answers for the number of Cesarean sections possible to have in one's life.

It was clear that none of the women were attending birthing classes outside of the allopathic system and were getting their knowledge solely from prenatal appointments. Sofia, my informant who had used a variety of doctors for her prenatal appointments because she moved from a larger city, discussed confusion about hearing different advice.

According to one doctor they told me I can't eat any sugar, coffee, or horchata and they said I needed to limit my fat; I can't eat sabritas. But in the clinic they didn't tell me that. The other doctor said you have to eat everything you can and so I think well who is right? I don't know which to listen to.

Unlike many of the other women I interviewed, Sofia and her husband owned a car and 
had lived outside of Pisté for several years. Sofia had the financial means and the allopathic exposure to feel comfortable with doctors but she still emphasized that they did not give her enough information.

I think more than anything the pregnant woman wants someone who listens to her because when you're pregnant everything is new and everything that happens, you think 'what could happen?' I feel something and I think what is happening with me? When I talk to the doctors I say I have this and I have that and this happened to me and the doctor says no, it is normal, it's normal, it's normal but it is a big change and you won't know what is or isn't normal.

Not only did I see a lack of outside research and some confusion about the allopathic birthing model, but there was also a devaluing of the parteras' knowledge from the women who were using allopathic medicine. Sofia's husband was also there when I interviewed her and he chimed in to characterize the advice of the partera:

There are a lot of old beliefs. Like they say when you are pregnant you can't lay down in the hammock with one foot on the ground because the baby could fall.

\section{Expectation}

I attended a prenatal appointment with Sofia and her husband. We drove to the larger Seguro Popular hospital, which was about an hour away. Once there, we checked in and then waited. While we were waiting there were always at least 50-70 people sitting in the hallway waiting as well. There were only six nurses there organizing the check-in process. Sofia explained to me that if you miss your name being called then you will be put all the way at the end of the list again. When I commented about the number of people waiting, Sofia told me there were normally three times as many people in the other hospital. We ended up waiting four hours until the nurses finally called Sofia's name. The cultural concept of time is different in Mexico, 
so time cannot be viewed accurately with an American lens, however, the length of time necessary certainly is a barrier for populations who must take off work or travel long distances to the hospital. Once we got in the appointment, it lasted a total of ten minutes. Afterwards, Sofia complained that the obstetricians were students and that they told her something different than the previous doctor had. She never mentioned the wait time as abnormal or the fact that they weren't shown the ultrasound or given any preparation information for the labor process even though she was a couple of days away from her due date.

It was helpful to view my informant's reaction to the appointment in comparison to my own reaction. I was appalled that the doctors were gossiping about unrelated topics while performing the ultrasound on my informant. They seemed distracted and uninterested and did not offer any explanation or support to her. Sofia has learned about pregnancy through her job working with women in rural areas and preparing them to be mothers. She said "I was worried because there are so many changes to the body during a pregnancy and the doctors just say everything is normal," but she cited the things she teaches in her mothering class as making her feel more comfortable about the process. Although she was unhappy with the Seguro Popular doctors, she never expressed the thought of switching to another obstetrician or going to another location for her pregnancy, which reflects a lack of a consumerist model of healthcare. The absence of a consumerist model of healthcare - and therefore the ability to switch practitioners manifests in the discussion of the power dynamic between the expecting mother and the practitioner.

Although there are too few doctors in this region to develop a consumerist model of healthcare, the traditional expectations of the woman are changed in the allopathic setting. Luisa who had her last baby with an obstetrician even abandoned the postpartum practices she was so 
adamant about with the partera.

The woman has just had her baby she is weak so because of that we take care of her and her baby, but after 40 days after the birth they can leave and go out on the town. [Q: Did you do this after your birth with a doctor?] With the doctor, no, not with the doctor.

She seemed almost confused as to why I would think she would continue with the postpartum practices when she had given birth in the hospital. Her response shows an aversion to mixing the traditional and allopathic models. Once the woman begins using the allopathic model, as long as the resources are available, she will approach it with no prior expectation and will abandon her traditional knowledge in the allopathic framework.

Power

In speaking with women who used allopathic medicine, they almost all mentioned the value of the doctor's technology. They demonstrated a trust in technology and the advanced medicine of allopathic practitioners even if they had to wait for a long time and did not have a comfortable experience. This response showed they placed a higher value on outcome and technology than on comfort or the experience itself. Informants also expressed that allopathic medicine can cure certain things quickly that traditional medicine can not address. One instance of this is called estrecha, which was described as a phenomenon when the woman's body cannot open wide enough to have a child, in which case a Cesarean section is necessary. The uses for allopathic medicine all seemed outcome-oriented, whereas the traditional medicine uses were more holistic or spiritual. This phenomenon demonstrated that women relied less on the doctors for a healer-patient relationship and focused more on the birth outcome. Maria Victoria said "doctors help you more because they give you medicine, parteras don't give you medicine." 
Similarly, Francisca, from a smaller town outside of Pisté, said:

In the clinic here, there aren't a lot of doctors and they never have enough medicines. They really only help with diarrhea and vomiting not other illnesses. I don't bring my children there because you have to wait too long for an appointment and then there isn't medicine.

The town where Francisca lived had a smaller clinic, which frequently ran out of resources. Questioning why women went to the clinic allowed me to see that the women were currently only placing value on the allopathic medications or technology and if the medicine ran out they had no interest in the allopathic model.

While many of the women complained about certain aspects of using the allopathic resources for their prenatal and birth experiences, they played a passive role, never questioning the advice of the doctors or showing an inclination to change the situation they were faced with. In Sofia's prenatal appointment, the doctors performed an ultrasound but never paused to show her. Sofia later mentioned this, although, during the appointment she did not show the inclination to ask for what she wanted. Even Luisa, who had given birth eight other times, did not attempt to use her experience as leverage or try to have a similar maternal birth experience as she had in her home when she gave birth in the hospital for her last pregnancy.

It was really hard because I'm not used to that, all 8 of my other children were with a partera and in a hammock. I was really uncomfortable in the bed, it wasn't a normal bed. It was really skinny and all you can do is put your feet in the apparatus on the sides. They lift up your leg and put it in the apparatus and lift the other one and put it in the other apparatus so your legs are open. The bed is small so you can't move.

She sounded powerless because the allopathic practices were unfamiliar, so she thought she just had to do whatever they told her to do.

\section{Louisville, Kentucky}

The initial questionnaire results in Louisville included 96 responses from women aged 
19-64 with an average age of 35 . The results were more racially and educationally diverse than the population in Mexico, and the city is also much less culturally homogeneous. The questionnaire reflected that women sampled from this population have a variety of resources in Louisville for birthing practitioners. They also have a variety of motivations for seeking out those types of birth practitioners.

While the racial diversity of the survey responses was low, the educational background and income status of respondents varied. The questionnaire demonstrated a wider variety of birthing options for women in Louisville than in Pisté. The options available are a homebirth with a "lay" midwife, a hospital birth with a Certified Nurse Midwife, a hospital birth with an obstetrician either vaginally or with a Cesarean section. While not available in Kentucky, other areas of the U.S. also have birthing centers for midwifery, comprising an option midway between a hospital birth and a homebirth.

The questionnaire asked about factors that were influential to the women in choosing the birth environment. Women were asked to pick their top three factors. Some of the women chose fewer than three, some chose more than three, and some wrote in their own factors. A "desire for birth with no medical intervention" was the factor chosen most frequently. This factor is representative that the population surveyed was skewed towards an unmedicalized ideal of birth. The next two most frequently chosen factors were "availability/access to provider" and "cost of care/insurance coverage." Many of the women who answered the questionnaire and indicated a write-in "other" option, added individualized information such as desire for a VBAC (vaginal birth after a Cesarean section) or an individual medical issue which complicated the birth. While most of the other responses were individualized, six of the women wrote in a desire for control or decision-making ability as an influential factor. 
There were 15 interviews conducted with women ranging from 25 to 60 years old, with an average age of 36 . The interview data may have been skewed because the women who were interviewed were self-selected and interested in speaking about their birth experience. Although all interviewed women volunteered to participate, the women represented all of the methods of birthing, each education level given, and each income level given.

Through the interview process it was possible to better understand the reasons behind the different birthing methods indicated on the questionnaire. Not all women want an unmedicalized birth even if they have done extensive research and taken a birthing class. When asked what their birth meant to them, some of the women I spoke to said they thought birth should be an empowering experience where a woman is able to allow her body to function the way it was designed to function. One woman said, "I just wanted it to be nice and calm and beautiful and loving," while others expressed that minimal pain was their priority and another woman said, "I was just glad to get it over with." Some of the women expressed wanting to take control of the birth. The women with this goal in mind often expressed that obstetricians were not respectful of their wishes and they disliked being told what was necessary during labor. Other women I interviewed preferred to let the birth practitioner take control during labor.

The diversity of goals for birth and varied explanations of 'the perfect birth' supports the idea that the ultimate maternal birth experience is not likely to come inherently from a particular method of birthing such as non-medicated vaginal birth but rather it may depend on the personality and preferences of the individual woman. Although the women I interviewed expressed different preferences for birth, they all spoke about pregnancy with an illness narrative. They all acknowledged medical relevance to the process and agreed a health practitioner was necessary for the birth. Some of the women spoke in less medicalized terms 
such as calling the contractions "surges," but still believed a medical professional was necessary for the treatment/birthing process.

\section{Knowledge}

The women interviewed in Louisville said very little birth guidance was given in the prenatal appointments and sharing of knowledge was even a point of conflict for mothers who were pushing back against the authoritative practitioner knowledge in the allopathic model of care. After her Cesarean section, Jenna started researching about VBACs (vaginal births after Cesarean section), to prepare for the birth of her next child. Jenna said:

I had gone to the ACOG website and gotten the stats and everything so I knew what my numbers were. I had even found a VBAC calculator. You put in certain stats like your weight, your race, your age when was the last time you had a C-section and how many you had.

When she returned to her OB/GYN 3 years later and pregnant for the second time, things were very different. Jenna said her OB/GYN

was all doom and gloom and she even quoted me a number that was not correct.... if I hadn't done all this research on my own I seriously would have left there feeling like let's schedule the C-section my uterus will explode and my baby will be in my stomach. Even though she said she was "sobbing because I absolutely adored her," Jenna switched from her $\mathrm{OB} / \mathrm{GYN}$ to a midwife practice because they were willing to support her VBAC birth. Jenna said, "I felt a right to information that was being infringed upon," demonstrating the allopathic value of knowledge which comes from the allopathic practitioner, not the woman.

While the allopathic birthing model has less accessible knowledge, from many of the interviews I saw trends of women taking more interest in researching their own birth knowledge and demanding the knowledge being shared in appointments because of their consumer power. When describing the appointment with a midwife, Jenna shared: 
She laid out the risks and benefits of VBAC, a planned C-section and of an emergency $C$ section. I couldn't have asked for a more well-rounded consult and that's what I really, really liked about seeing her.

Many of the women interviewed took additional birthing classes such as Hypnobirthing, Lamaze, Bradley Method, and Empowered Birth classes. Many of these informants were able to compare the information that the hospital birth class offered to the information from the outside classes. Every woman who had taken the hospital birthing class expressed that it was either insufficient, covered the wrong topics, or not inclusive of women who were attempting a non-medicated birth. Jenna's doctor even told her if she "wanted a natural birth she said you should take a birth class outside of the hospital. She said all the hospital is going to teach you is how to be a good patient."

Women also explained the hospital class was less effective because it took place in a large auditorium with many other women making it difficult to ask questions and receive individualized advice. One woman who had only taken the hospital course told me she was surprised when they told her to keep pushing after she had given birth because she was never told about the birth of the placenta. She also expressed that the class did not prepare her for what labor would be like or the self-care necessary postpartum. This remark shed light on the accessibility of information provided about birth if the woman is unable or not inclined to do research on her own.

\section{Expectation}

Many of the women I spoke to in Louisville had strong expectations about the way their birth should go. The strong expectations often correlated with the amount of outside research they had done or whether they had taken an outside birthing class. Several of the women I interviewed took the same birthing class and described to me a card game they played. 
It gives you like all of these cards and they're two-sided like on one side it would say 'my doctor delivers' and on the other side it would say 'on call doctor delivers' or boy or girl or use of forceps or no use of forceps so you lay them out and you lay out your perfect birth. As you go through you lay them out to make your perfect birth and slowly [the instructor] goes give up 2 give up 3 until you're left with only 3 which would be your top pic so for one you have to prioritize.

Jenna described this game to me to explain how her expectations for her birth were not met.

So the first things I gave up were baby coming before due date to baby coming after due date, instead of it being a boy like we had been talking about it being a girl that's not a big deal. The last three I had were a vaginal birth, immediate skin to skin and breastfeeding.

As described in the previous section, for her first baby, Jenna was told she had to have a Cesarean section.

So I mean already two got thrown out the window and then the third one like that was really, really, hard because it was like I didn't get to keep any of the cards. None of my cards worked, this is so stupid this is not fair I did all this research for nothing.

Many women who were not able to have the type of birth they wanted expressed similar sentiments as Jenna did. It seems that the knowledge they are able to bring to the table about their birth empowers them to expect a certain maternal birth experience.

In the allopathic birth model, the expectations of a mother are often written in a document called a birth plan. Many of the women interviewed spoke of creating a birth plan with their birth practitioner during prenatal appointments so that their preferences could be respected during labor. The birth plan details the types of medical interventions the mother wants, the methods of laboring, who can be in the room during the birth, and whether or not the baby will stay with the mother right after the birth. After comparing the perceived birth satisfaction levels of mothers, it was clear that whether or not a birth followed a mother's birth plan was often aligned with their satisfaction, but was not the primary reason for their satisfaction. 
One woman, Georgia, who had a birth plan of a vaginal birth with no medication ended up with a Cesarean section yet still expressed satisfaction about the birth. Georgia went to the hospital after feeling like something was not right with her baby. After hours of monitoring, an ultrasound and attempt to start labor by manually breaking the waters, Georgia's obstetrician said she needed a Cesarean section. Georgia said:

I did feel like she did as much as she could to try to give me the birth plan. She broke my water first to try to start labor and she was willing to give me some time I think it was maybe 13 hours before she decided to do a C-section, so I do feel like I was pretty supported.

Although having a Cesarean section did not follow her birth plan, Georgia expressed feeling informed about why the decision was being made. She remarked that, the obstetrician "did kind of ask me and let me say okay yeah, let's do it" so she felt in control of the decision. This supports the influential factors such as knowledge and power on the maternal birth experience in addition to expectation.

Kate had the same birth plan as Georgia and achieved the basics of her birth plan but was not satisfied. Even during prenatal appointments she already expressed discontent saying, "I was not happy with her but I didn't feel like I had the choice to leave." Because of minor complications to her pregnancy, she was going to the hospital regularly for fetal monitoring in the last weeks of the pregnancy. At one appointment she said the nurses

told me I needed to be induced because the baby was in distress and I said what happens if I wait and they told me they would only let me leave the hospital if I signed all these forms saying they are not liable for her death.

Kate ended up staying in the hospital that day to have a "modified induction so they wouldn't push all the drugs right away." During labor "they threatened to give me a C-section because I wasn't progressing as fast as they wanted." Even though she did end up having a vaginal birth 
with no epidural, as soon as she finished describing her birth story to me she said, "I was very unhappy with her birth. The whole thing felt very business-like and it was very industrial so I was not happy with that situation at all." Expectation is not the only factor for a positive maternal birth experience, but it appears that a power dynamic between the woman and practitioner is also important. I asked her who was in control in the room and she said the doctor and head nurse although she wanted to be in control she "felt like anything I said was ignored anyways." This push for a more collaborative role in the birthing process demonstrates an expectation of a doctor-patient relationship that is unmet.

The discourse used by the birth practitioner during labor seemed to influence whether the mother spoke positively or negatively about the birth. The birth practitioner-patient relationship was commonly brought up in interviews. Many of my informants compared their births based on how the birth practitioner treated them and referenced those experiences as a reason they switched practitioners. Kate said, “it's kind of a common thing that people being pushed into stuff they don't want to do and being bullied so I definitely would get a different $O B / G Y N$."

In general, many of the women felt that the obstetricians were more domineering in their discourse. Women referenced being told they had to have particular interventions or told they had to labor in a certain position. One woman told how an obstetrician performed an episiotomy on her without asking and instead stated what she was doing while she was cutting. Women said similar discourse was used for labor checks, Pitocin injections and artificial rupture of the membranes. In addition to the authority shown through discourse, obstetricians and nurses were often described as pushy or even bullying. Kate said, 'that doctor said the words 'dead baby' to me over 10 times and that phrase to a super-pregnant women is just not right." She felt it was unfair to use such scare tactics without explaining the medical need for her induction. When 
asked about words they associated with OB/GYNs, the women emphasized medical aspects as well as words like "controlling" or "pushy."

Power

In the allopathic birthing model, the obstetrician holds the majority of the power in making decisions about the birth. Many of the women I spoke to expressed wanting a more active role in their birth experience, and, while the midwifery model was described as more collaborative, I heard many stories about obstetricians taking this power away from the woman. The birth plan as described in the previous section was similar to a contract that the woman could use to try and hold the allopathic practitioners accountable for respecting her preferences. Many of the women described the power of the allopathic practitioner in relation to violations they made to their birth plans.

One woman, Sarah, who planned to have a midwife delivery, ultimately needed a Cesarean section. She was upset but able to come to grips with this decision because she agreed with the midwife that there was nothing else they could do and she was given time to understand the change. During the Cesarean section, the obstetrician made a second cut outside of the normal cut but even five days after the procedure he had not informed her of this deviation from the normal protocol. When the midwife came in to check on her she told her about this information and explained that this meant she would have to have a Cesarean section if she had another baby and there was not a chance of having a VBAC. Her Cesarean section was 2.5 years ago but Sarah was still very emotional about it:

We don't even want any more kids but the fact that that choice was taken from me was really a hard pill to swallow and it still is. Like, how easily did he make that decision to make that second cut? how hard did he try? and what was wrong? and what else 
could have been done to not have the second cut if I did want to have a second child? how many people does this happen to that they get that choice taken from them with that second cut? .... everybody says things to you like 'you have a healthy baby so it's fine' you know and that's true of course we wanted a healthy baby but there was more to it than that, you know? Especially when that's not your plan and it's the opposite of your plan so that's our story it did not go as planned.

The power the obstetrician demonstrated exemplified that he could make a life-changing cut without informing Sarah at the time or even after the surgery.

Jenna, who also had a Cesarean section, also expressed feeling like her role was not participatory.

I really wish I had been allowed to wear my glasses it was nuts I couldn't see anything my baby was a blur. [Q: Why couldn't you wear your glasses?] I guess maybe like a contamination thing? I don't know because like they immediately took my glasses off and was like who do I hand these to and I was like I'm sorry but I can't even process what you're saying you took my glasses, I can't see anything. So when they held him up above the curtain I couldn't see anything, my baby was a blur.

Jenna just assumed there was a particular regulation that explained why she could not wear her glasses in the surgery but she felt no power to ask for her glasses because in that setting only the allopathic practitioners dictated the rules.

One marker of the consumer qualities in the allopathic birth model is that women have different options for birth. Not only can women give birth in a hospital with an obstetrician but they can also have a midwife in a hospital or even a home birth delivery. These options arise because the consumers, mothers, have individual expectations about their births. While the OB/GYNs were often described as Kate depicted, women who wanted more power or control in their experience often elected for a hospital midwife or home midwife birth.

In general, women described midwives with more caring references. One woman 
switched from an obstetrician to a hospital midwife because of the more individualized care she perceived just in the prenatal appointments. Women expressed that the midwives, even in the hospital, asked permission before medically intervening and were suggestive in an inviting manner when they influenced the labor process, instead of mandating that a woman needed to do something. The women also said they felt the midwives explained the reasons behind their suggestions more clearly so that the laboring mother felt in control of the situation. When asked about words they associate with midwife, women gave synonyms to caring or support as well as phrases such as 'giving confidence'.

The sample I interviewed was skewed towards women who were more involved in the birthing community in Louisville and felt dissatisfied by the obstetrician model of care. Consequently, I was able to interview two women who had homebirths. Homebirth in Louisville is not legal because the Certified Professional Midwives are not licensed in Kentucky. The women that I interviewed were so dissatisfied with the birthing options in a hospital that they opted for a homebirth. Both women decided to become advocates for the birthing community in Louisville by being a part of the Kentucky Homebirth Coalition or by becoming a doula. I do not believe these women were representative of all perspectives, but they were great sources of information into the needs of the population of women not being served by the hospital.

In describing their prenatal appointments and homebirth experiences, women expressed a more informed perspective about birth. Because they had to overcome obstacles to have a homebirth, they had done more research and were informed through lengthy prenatal appointments by the midwife so that they were well prepared to understand the events of labor and birth. This means there was a more collaborative sharing of the birth knowledge where the woman's urges or body signals were valued in the experience instead of the regulations of the 
practitioner. The women expressed feeling in control and being allowed to do whatever their body told them they needed during labor was the main reason to elect for a homebirth. The medical interventions such as fetal monitoring, Pitocin injections, labor checks and vital sign monitoring were still present in the environment but in a less dominating way. The women said the midwives always asked permission before any medical intervention and allowed the woman to have deciding power over when and how things would happen. The power dynamic between the mother and practitioner is more equitable, differing from the stereotyped allopathic model. With this, there was also a component of trust that was described to be essential. In comparing the ways the women who had homebirths spoke about their expectations of birth to the expectations of a woman who I interviewed that seemed disinterested in being in control during labor, it was evident that this method was not for everyone.

\section{DISCUSSION}

Analysis of the ranges of viewpoints observed in the interview process brings up three major themes: knowledge, expectation and power. These can be used to understand the dynamics of the maternal birth experience and highlight key ways in which the transition between traditional medicine of the partera and allopathic medicine of the obstetrician changes the maternal birth experience. As the parteras fade away from practice in the Yucatán and Seguro Popular makes allopathic medicine accessible to all, the birthing model shifts from traditional to allopathic changing the maternal birth experience. In the same way, as midwifery is rebranded in the United States, challenging the hegemony of the obstetricians in the birthing field, the maternal birth experience in regards to knowledge, expectation and power undergoes a transformation as well. 
Table 1. represents a summary of the events in the transition from traditional to allopathic medicine. Two columns detail the expected status of knowledge, expectation and power of the respective birthing models, and the last column reflects the transition between the two. The following sections of the discussion will address the specific components of knowledge, expectation and power as well as the transition as a whole.

Table 1. Summary of Transition 


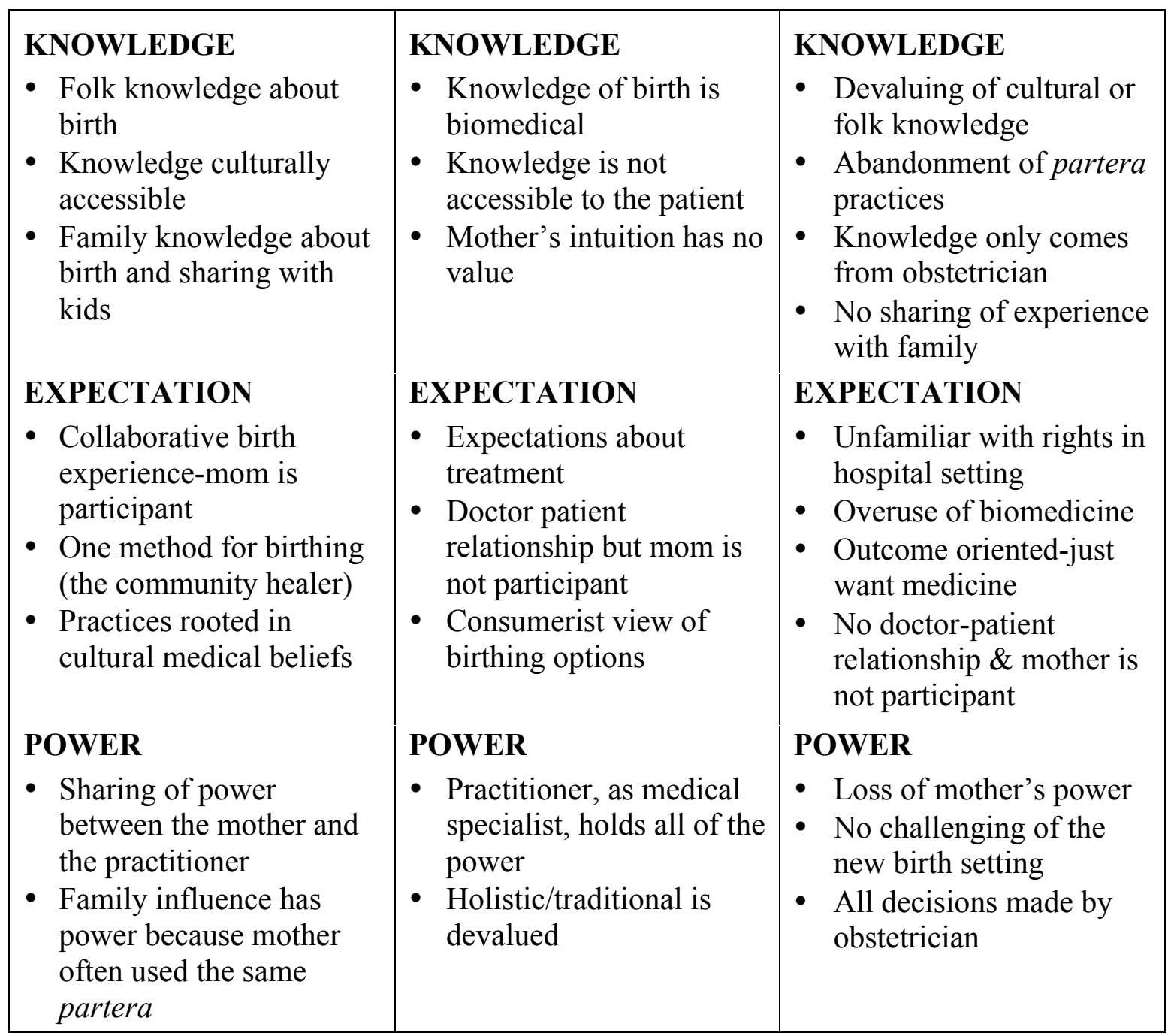

\section{Knowledge}

Knowledge about pregnancy and the birthing process is valued differently in Pisté versus Louisville. In Pisté, with a partera birth, the knowledge about the birth practices is rooted in beliefs that are held by all in the culture. The partera followed traditional practices so the mother also had an understanding and belief in the actions the partera would advise for the pregnancy. The partera knowledge is passed on to family or apprentices who are interested, whereas the allopathic model is more technocratic. In the allopathic model, the woman's knowledge has no value in the interaction, as demonstrated when the $\mathrm{OB} / \mathrm{GYN}$ disregarded the VBAC statistics Jenna was citing in her appointment. 
In the transition away from traditional medicine, the devaluing of folk knowledge would be expected. This occurrence was observed societally through the lack of new parteras in the area as well as in Luisa's abandonment of the partera prenatal and postpartum practices when she switched to using an obstetrician. Sofia said that if you give birth with a partera, the state will not recognize your child. The State's denial of the legitimacy of the partera is synonymous to what occurred in the United States with midwives. In fact, the remnants of this holistic medicine devaluing is seen in the United States by the laws restricting midwifery practice in Louisville.

As the woman begins to use allopathic medicine, the value of her cultural knowledge about childbirth seems to be lost. The allopathic birth practitioners have gone through, often extensive, training that extends only to the students of that career. The mothers using the allopathic model of birth practitioners are not familiar with the reasons behind the practices and the medical knowledge supporting the practices is inaccessible to the mother. The women interviewed in the U.S. were able to employ outside research techniques and birthing classes to gain knowledge about the birth practice; however, these things are not yet widely available in Mexico. The inaccessibility of birth knowledge leads to a change in the locus of power in the birthing process.

\section{Expectation}

In a transition from traditional medicine to allopathic medicine, the expectations of the patient will change. Due to the lack of familiarity with allopathic medicine and limited physician options, the woman will not have a strong expectation of her rights in the allopathic setting or the relationship she should have with the practitioner. The older women I interviewed in Pisté told me about times when there was not a doctor in the town or they were much less accessible 
because they were very expensive. In contrast, many of the younger women in Pisté said now they would not know where to find a partera even if they wanted to. The increasing use of allopathic medicine combined with the decreasing number of parteras forces the women in Mexico to exclusively use allopathic medicine as their birthing option. In Mexico, this transition is occurring and the cultural norms about relationships between a doctor and a patient are not as developed.

The consumerist model of healthcare in Louisville, combined with the high number of hospitals and allopathic options available, allows a woman to expect a certain doctor-patient relationship from her birth practitioner. In Pisté, the limited allopathic resources available also mean the consumer model does not yet apply. The lack of expectation is demonstrated in the way Sofia, the informant I accompanied to a prenatal appointment, was complacent about the wait time for her appointment and did not demand more explanation from her doctors. Her complacency contrasted with the expectations of women in the U.S., who assumed they would have specific options such as such as the ability to have their birth plan respected, ability to dictate who is in the room during birth, ability to control what happens with the baby right after birth, etc. The women in the U.S. are more familiar with the allopathic model and therefore know their general rights in that setting and are able to demand a certain relationship as well as medical treatment.

The women I interviewed in Mexico showed a high assigned value of medical technology while some of the women in Louisville seemed to resent the technological interventions in birth. Because the consumer model of healthcare was not apparent in Pisté, based on fewer doctors present and a restrictive insurance system, women were more focused on the outcome from the interaction with a physician rather than the relationship or experience they had. One woman told 
me that doctors are better purely because they give you medicine, another woman said that she doesn't go to the clinic in Dzitas because they are always out of medicine so there is no point. Because of the different experiences with medicine in general, the women from Pisté who are attended by an obstetrician may not be as agitated as a woman from Louisville when presented with little agency or decision-making power about the birth plan.

\section{Power}

In the allopathic model of birthing, the obstetrician holds the power. The physician is given the power to intervene when they decide it is necessary because they possess the training and the technology. The power dynamic allows the obstetrician to make decisions without fully consulting the mother, permitting them to be more authoritative in the relationship because only their allopathic knowledge is valued. Many women I interviewed related all negative aspects of their birthing environment to the disparity in power held by the obstetrician and the laboring mother. In interviews, many women said a doula, a knowledgeable birth companion, is necessary because they are able to advocate for the laboring mother when a practitioner is deviating from the birth plan.

With the North American midwifery model of care, there is also a slightly more holistic view taken. The power is shared between the mother and the midwife because the midwife has experiences as well as allopathic knowledge but the mother's knowledge of body signals is also valued. This shared power is demonstrated in the more collaborative environment described by mothers who were attended by a midwife. Collaboration is a main component of the midwifery model that women praised in my interviews. They said that it allowed them to feel more in control during labor and more empowered afterwards.

The partera model of care is even more holistic than the midwifery model of care. This 
is due to the fact that the illness beliefs differ. The Maya illness beliefs emphasize that complications can be caused by an imbalance unrelated to the physical symptom. The root of many partera practices is to maintain the balance. The laboring mother may know just as much about the details of the practices as the partera because they share a common belief system. In Mexico, the women lose their participatory role in birth as they transition from holistic partera model to the allopathic obstetrician model. The heightened value of the technology of the obstetrician — partially because of the novelty — allows the women to accept this loss of power. This acceptance was observed as women, who had previous births with a partera and then a birth in a hospital, did not express a desire to challenge the hospital practices although they were less comfortable or less convenient. While women reported a collaborative environment during labor with a partera, women such as Luisa who used an obstetrician for her last birth spoke of discomfort giving birth in a hospital bed with stirrups but never expressed the thought of challenging that practice. Based on the events throughout the history of midwifery in the U.S., it is possible that as the birthing model transitions farther to allopathic care there may be a resistance where women realize and attempt to regain their power in the birth experience such as is happening now in the U.S.

While this transition describes a societal shift in expectation, knowledge and power in regards to the maternal birth experience, on the individual level there is variability with regard to the desired degree of participation in the birth experience. As demonstrated in the results, not all women in the United States want a vaginal birth with no pain intervention. Some women do not want the responsibility or risk of a homebirth while others crave the empowerment of taking control of their birth. The transition described applies only at the societal level and I acknowledge that within societies there will never be homogeneous views. Just as there are some 
rural areas in the Yucatán where they still rely solely on the town partera, there are some women in the United States who choose elective Cesarean sections primarily for reasons to maintain integrity of the vaginal and pelvic floor, seen by some as vaginal vanity (SagadyLeslie 2004).

In addition, while the reclaiming of control over birthing by some sectors of the population in the United States is occurring under midwifery movements, there are certainly populations of women who do not want a birth with a midwife. The U.S. component of the transition applies to the population of women who feel they are not best served by the allopathic birth practices. The transition may be helpful in predicting and analyzing the way the expectations of women line up with the available birthing practices. While outcome-oriented views of the birthing experience may consider that any model of care is successful if a healthy baby was produced, the psychosocial experience of the mother during labor should be further investigated for optimal birth outcomes. Stress induced from conflicting goals between the laboring mother and the birth practitioner can harm the psychological experience of the mother during labor. There have been many studies published linking the psychosocial framework to physical health outcomes.

The Louisville women who expected to have control during labor and gave birth in a collaborative environment expressed very positive outcomes speaking about the empowerment and transformative nature of childbirth. A woman who expected to have control during labor but was forced into an emergency Cesarean section expressed extremely negative outcomes. Her experience was so negative that she felt the motivation to share it in the comments section of the questionnaire and described her experience as a "chaotic, scary, violent birth.” Another woman who expressed wanting the obstetrician to have the decision-making power during labor ended up describing the birth experience with an $\mathrm{OB} / \mathrm{GYN}$ as "loving." 
While the data from this research does not extend this theory to correlating a certain stage in the transition with the physical outcomes of birth, another study titled Stress, Pregnancy, and Motherhood: Implications for Birth Weights in the Borderlands of Texas (Fleuriet and Sunil 2016), demonstrated physical impacts of stress during pregnancy. The conclusion from this article was that for Mexican immigrants over time the changing meaning of motherhood due to assimilation incorporated more stress during pregnancy, which was associated with lower infant birth weight. While correlation, not causality, was proven in this study, it supports the theory that psychosocial health during pregnancy and labor is important for physical birth outcomes. This study is also relevant to this thesis because it demonstrates the way culture impacts the different psychosocial frameworks of Mexican women and American women.

\section{Transition and Transformation}

One of the first observations I made when I was researching in Pisté was that birthing options were in a state of change. Change was evidenced because of the expanding allopathic resources, new clinics being introduced and difficulty finding a partera as well as in interviews with women. In Mexico, the notable trends in responses were based on generational and geographical differences. It was found that birth practitioner choice differed greatly across generations. Based on the questionnaire used in this study, Mexican women above the age of 50 all used a partera for their deliveries and women under 50 used an obstetrician. This statement is generally true in Pisté but varies based on geographical location. The only case that did not fit this was a woman from Pisté, the more urban town sampled, who was 58 and used an obstetrician. The Mexican women in more rural areas have a higher use of parteras than the women in urban areas. This phenomenon was described in an interview with Sofia, who teaches a parenting class in rural towns outside of Pisté. I asked Sofia if the women she works with go to 
the city for their births. She said:

Yes, some of the women, depending on the town they live in. When they live in cities they are more open-minded and use the doctor more but when they're in small communities the people don't go to the doctor. [Q: Do they use parteras?] Yes, they prefer parteras and the natural medicines or what the grandma says.

The women in urban areas were also more likely to have Seguro Popular, the Mexican health insurance, and use the town clinic resources. Luisa, who was old enough to remember when there were no doctors in the town she lived in, but young enough to have had her last child with an obstetrician, said she thought Seguro Popular was the reason for the partera decline. She said:

Now because everything is medical and everything is Cesarean the people don't do this, the women now don't do this. It's really rare now for towns with parteras. [Q: Are there parteras outside of Pisté?] Yes, on the farms where there aren't clinics or doctors. They exist.

As I searched and failed to track down a partera in the region to interview, it became evident that while the cultural significance of the partera was still strong, their acting power had dissipated in this area of Mexico. The parteras cited in the work of previous students at the field school had all passed away. I even went to a town outside of Pisté to find a woman a couple of people recommended and she had passed away several months prior. That no women in the younger generations were interested in becoming parteras, demonstrates a diminishing value of that cultural knowledge. Many women said with more doctors around fewer people have trust in the parteras and fewer people want to learn. For some, this was the first exposure to allopathic medicine that they had and they were more open to it because it was free. Luisa had seven babies all with a partera but used a doctor for her last birth because there were no parteras nearby. She said her grandchildren both had Cesarean sections because they do not believe in the partera and 
thought she would hurt the baby.

The partera specialty is passed along to interested apprentices, often children. The sobadora who demonstrated on me was taught by her mother and helped in the delivery of her younger siblings. When asked about the process of learning how to sobar, she said, "it was easy to learn because I was interested. But you have to want to learn." She said she was disappointed none of her children were interested and said that is probably why the practice is less common because the apprentice has to be fully committed in order to learn. The decline in parteras forces the women to use the allopathic birth model, which alters the maternal experience greatly. Understanding the transition from traditional to allopathic birth practices will be important in predicting challenges mothers will face.

On the other side of the transition, the Louisville population, which has been relying on allopathic birthing models for the majority of births, is experiencing a type of reversal of the transition. In the allopathic birth model women are now rebelling against their loss of a participatory role and using their power as consumers to demand specific things from the birth experience. Because of this midwifery is gaining popularity.

One observation from my interviews of how women are attempting to take charge again is the creation of the birth plan. Many of the women I spoke to preferred the midwifery model of care because it involves the woman more in the process. Emily explained saying:

The way they care for you during labor is so different they just spend a lot of time and just sit back and watch and don't interfere unless necessary so just having her there and when I would say something like I'm not sure I can do this or I think I need help she said you're doing it, you're doing a great job you don't need any help you're doing everything you need to be doing and I was like oh okay. Just having that support and her being supportive of my preferences and knowing what my preferences were and being proactive with that helped. 
In addition to the birth plan, mothers are using their consumer power to demand specific resources. After her obstetrician refused to support her VBAC with no medical explanation Jenna said:

I left and I was like sobbing because this doctor, I absolutely adored her. She had been the doctor through my miscarriage and the doctor who tried to help me get pregnancy and had been through my doctor all through with my first baby and, um, she wasn't the doctor for me anymore.

In Louisville, the University Hospital recently added Certified Nurse Midwives to their staff and the women I interviewed raved about them, happy to not have to go to Indiana for midwifery care anymore.

\section{CONCLUSION}

The Yucatán birthing environment is transitioning away from holistic medicine by devaluing the partera knowledge, accepting any obstetrician relationship and allowing biomedicine to hold the power during birth. In the opposite direction, the United States birthing environment is further along in the transition, and is now reclaiming the values of holistic medicine by making birth knowledge more accessible to women, demanding certain birthing resources from hospitals and reclaiming the maternal power during birth to create a more collaborative experience. The cross-cultural comparison allowed a wider frame of reference to view these shifts in beliefs and practices as transitions on a continuum.

Although allopathic influence is relatively new in the regions of Mexico where this study took place, the universal healthcare system is being heavily supported through media campaigns and the construction of clinics in smaller towns. With the increase in allopathic exposure, the expectations of women in their relations with birth practitioners may change. As the transition 
into allopathic medicine becomes more pervasive, a movement to regain holistic aspects may take momentum. Already in Mexico there is a new midwifery movement to increase parteras' allopathic knowledge (Anderson, et al. 2004) similar to the one that occurred in the United States to create the Certified Nurse Midwife model of care. The younger parteras have been organizing and partnering in some instances with allopathic practitioners to increase knowledge about birth complications and use of allopathic interventions. An interesting continuation of this study would be to return in ten years and investigate the progress of this transition as well as compare how the expectations of women in relation to their maternal birth experience have changed.

If the partera practice continues declining, the increasing accessibility of allopathic medicine through Seguro Popular means that Mexican women will soon be forced to exclusively use obstetricians as their birth attendants. This switch will cement the transition that has been described throughout this thesis. The transition is argued to have already started based on the dynamic changes in regard to the themes of expectation, knowledge, and power comparing the partera model and the obstetrician model in Mexico. Further comparison of these themes using the American maternal birth experience demonstrated that the United States is at a further stage in the transition where there is a revaluing of the holistic approach. The maternal birth experience is defined by the expectations a woman has about her birth, which are molded by the overall societal norms. As society changes over time, it is important to investigate how the expectations of birth change as well in order to accommodate the practitioner options that best serve the maternal birth experience.

As displayed through the case-studies described in the research results, not all women have the same desires for their level of participation in the laboring experience. For women who are dissatisfied by the hegemonic obstetrician birth model and wish to be in control during their 
labor, altered discourse used by the obstetrician and nurses may lead to a better birthing atmosphere and experience. The model of a birth transition between traditional and allopathic medicine can be used to understand the desired birth experience of women based on responsibility for knowledge, types of expectations and the power locus during birth. This theory identifies a new avenue of research into the discourses used between birth practitioners and women during labor. Future studies designed to interview women about their birth expectations, experience during labor and tracking the physical outcome of their birth may demonstrate correlations between a positive maternal birth experience and healthy outcomes. 


\section{WORKS CITED}

Salud.

Seguro Popular: Sistema de Proteccion Social en Salud, Vol. 2017: Secretaria de 2017 Frontier Nursing University: U.S. News and World Report.

Anderson, Barbara A., et al.

2004 Pathways of decision making among Yucatan Mayan traditional birth attendants. Journal of Midwifery \& Women's Health 49(4):312-319.

Bernard, H. Russell

2006 Research methods in anthropology: Qualitative and quantitative approaches.

Lanham, MD :: AltaMira Press.

Davis-Floyd, Robbie

2001 La Partera Profesional: Articulating identity and cultural space for a new kind of midwife in Mexico. Medical Anthropology 20(2):185.

Davis-Floyd, Robbie, and Christine Barbara Johnson

2006 Mainstreaming midwives: The politics of change. New York :: Routledge.

Dawley, Katy

2003 Origins of nurse-midwifery in the United States and its expansion in the 1940s. Journal of Midwifery \& Women's Health 48(2):86-95.

De Gezelle, Jillian

2015 Q'eqchi' Maya reproductive ethnomedicine. Cham :: Springer.

DuPré, Athena

2014 Communicating about health : Current issues and perspectives. New York ::

Oxford University Press.

Fleuriet, K. Jill, and T. S. Sunil

2016 Stress, Pregnancy, and Motherhood: Implications for birth weights in the borderlands of Texas. Medical Anthropology Quarterly.

Jordan, Brigitte

1978 Birth in four cultures : A crosscultural investigation of childbirth in Yucatan, Holland, Sweden, and the United States. Montreal ;: Eden Press Women's Publications.

Jordan, Brigitte, and Robbie Davis-Floyd

1993 Birth in four cultures : A crosscultural investigation of childbirth in Yucatan, Holland, Sweden, and the United States. Prospect Heights, Ill. :: Waveland Press.

Kitzinger, Sheila 2012 Rediscovering the social model of childbirth. Birth 39(4):301-304.

Kleinman, Arthur

1995 Writing at the margin : Discourse between anthropology and medicine. Berkeley :: University of California Press.

McCool, William, and Sara Simeone 2002 Birth in the United States: An overview of trends past and present. The Nursing Clinics of North America 37(4):735-46.

Miller, Amy Chasteen, and Thomas E. Shriver

2012 Women's childbirth preferences and practices in the United States. Social Science \& Medicine 75(4):709-716.

Redfield, Robert, and Alfonso Villa Rojas

1962 Chan Kom: A Maya village. Chicago, Ill :: University of Chicago Press. 
SagadyLeslie, Mayri

2004 Counseling women about elective cesarean section. Journal of Midwifery \& Women's Health 49(2):155-159.

Sargent, Carolyn, and Grace Bascope

1996 Ways of Knowing about Birth in Three Cultures. Medical Anthropology Quarterly 10(2):213-236.

Savage, Wendy

2007 Birth and power: A savage enquiry revisited. London :: Middlesex University Press.

Taylor, Janelle S. 2003 Confronting "Culture" in Medicine's "Culture of No Culture". Academic Medicine: Journal of the Association of American Medical Colleges 78(6):555.

Wolf, Jacqueline H. 2009 Deliver me from pain: Anesthesia and birth in America. Baltimore :: Johns Hopkins University Press.

Zacher Dixon, Lydia

2015 Obstetrics in a Time of Violence: Mexican midwives critique routine hospital practices. Medical Anthropology Quarterly 29(4):437-54. 


\title{
APPENDIX A: QUESTIONNAIRE Birth Experiences Survey
}

Investigators: Dr. Christopher Tillquist and Alice Darling

1. Email address *

2. Today's Date

Example: December 15, 2012

\section{Study Title: CROSS-CULTURAL INVESTIGATION OF BIRTH EXPERIENCE: A COMPARISON BETWEEN MEXICO AND THE UNITED STATES}

\begin{abstract}
You are being invited to participate in a research study by answering the attached survey about you birth experiences and background. There are no known risks for your participation in this research study. The information collected may not benefit you directly. The information learned in this study may be helpful to others. The information you provide will be used for a Senior Honors thesis comparing the birthing environment in Kentucky to Piste, Mexico. The survey information will help create comparisons between the populations who use differing birthing resources. Your completed survey will be stored in an online folder that is password protected and associated with a specific email address used only for this study. The survey will take approximately 10 minutes to complete.
\end{abstract}

Individuals from the Department of Anthropology, the Institutional Review Board (IRB), the Human Subjects Protection Program Office (HSPPO), and other regulatory agencies may inspect these records. In all other respects, however, the data will be held in confidence to the extent permitted by law. Should the data be published, your identity will not be disclosed.

Taking part in this study is voluntary. By completing this survey you agree to take part in this research study. You do not have to answer any questions that make you uncomfortable. You may choose not to take part at all. If you decide to be in this study you may stop taking part at any time. If you decide not to be in this study or if you stop taking part at any time, you will not lose any benefits for which you may qualify.

If you have any questions, concerns, or complaints about the research study, please contact: Alice Darling at 502-216-5153 or ajdarl01@louisville.edu.

If you have any questions about your rights as a research subject, you may call the Human Subjects Protection Program Office at (502) 852-5188. You can discuss any questions about your rights as a research subject, in private, with a member of the Institutional Review Board (IRB). You may also call this number if you have other questions about the research, and you cannot reach the research staff, or want to talk to someone else. The IRB is an independent committee made up of people from the University community, staff of the institutions, as well as people from the community not connected with these institutions. The IRB has reviewed this research study.

If you have concerns or complaints about the research or research staff and you do not wish to give your name, you may call 1-877-852-1167. This is a 24 hour hot line answered by people who do not work at the University of Louisville.

Sincerely,

Dr. Christopher Tillquist Alice Darling 


\section{Background Information}

3. First Name

4. First Initial of Last Name

5. Age

\section{Birthing History}

6. Number of pregnancies

7. Number of term births (babies born at 38-42 weeks)

8. Number of pre-term births (babies born before 38 weeks)

9. Number of abortions or miscarriages after 8 weeks

10. When was your most recent birth?

Example: December 15, 2012

11. Have you had a multiple birth?

Mark only one oval.

No

Yes, twins

Yes, triplets

Yes, more than triplets 
12. Use of Assisted Reproduction Technologies?

Check all that apply.

None

Yes, artificial insemination (Al)

Yes, In Vitro fertilization (IVF)

Other:

13. For your childrens' births, indicate all types of birth practitioners which have assisted you. Check all that apply.

$\square$ OB/GYN Physician

Midwife

Doula

Other:

14. For your childrens' births, indicate all of the following which apply Check all that apply.
Hospital birth
Home Birth
Vaginal Birth
Cesarean section

15. For your childrens' births, indicate all of the following which apply Check all that apply.

Epidural or spinal anesthesia

General Anesthesia

No medication

Labor-inducing medication (pitocin)

Unsure

Other: 
16. Please select the top three most important of the following factors that influenced your decision in choosing a birth practitioner

Check all that apply.

Cost of care/insurance coverage

Availability/access to provider

Desire for birth with no medical intervention

Partner/family pressure

Desire for pain intervention options

High risk pregnancy

Safety concerns

Religious beliefs

Elective induction or $\mathrm{C}$-section

$\square$ Other:

\section{Demographic Information}

This information will not be connected with your name. This information will be used to look at trends in populations that use particular birth practitioners. You may leave any question blank that you do not want to answer.

\section{Which state were you born in?}

\section{What ethnicity do you identify with?}

Mark only one oval.

White

Hispanic, Latino, or Spanish Origin

Black or African-american

American Indian or Alaska Native

Asian

Middle Eastern or North African

Native Hawaiian or Other Pacific Islander

Other: 


\section{Religion}

Mark only one oval.

Buddhist

Catholic

Hindu

Jewish

Muslim

Protestant

Unaffiliated

Other:

20. Highest level of education Mark only one oval.

Middle School

High School

2-year college degree

4-year college degree

Graduate Education

\section{Income Status (household income)}

Mark only one oval.

Less than $\$ 30,000$ per year

$\$ 30,000-49,999$

$\$ 50,000-59,999$

$\$ 60,000-99,999$

Over $\$ 100,000$

\section{Survey Conclusion}

Thank you so much for taking the time to complete this survey. After clicking submit you will be brought to a screen with details about setting up an individual interview with Alice Darling, if you are willing to participate in that portion of the research study. Any time you are willing to dedicate is very appreciated!

22. Before submitting, if there is anything from your birthing experience that did not fit a given question in the survey above please explain below if you wish to elaborate. 


\section{APPENDIX B: INTERVIEW QUESTIONS}

Can you tell me about your birth experience?

Pre-natal experience:

What type of guidance or help did you receive during your pregnancy and birth?

Did you have any family input on your pregnancy experience? Is anyone in your family in the healthcare field?

Had you ever seen a birth before the birth of your own baby?

Who was the most influential person for your birth decisions?

Did religion dictate any rules about pregnancy or labor for you?

In planning the birth of your child what were the most important factors to you? (ex: pain, use of medicine, people present)

How did you find your birth practitioner? Was availability a factor in your decision? Did you know them before your birth?

What were your biggest concerns surrounding your pregnancy and the birth of your child?

What ways did you prepare for your birth? (prenatal classes, meeting with a doula, reading books about pregnancy and birth, etc)

What did you want out of your birth? Anything besides a baby?

Did you make a birth plan?

How did you pay for your method of care? (healthcare insurance, out of pocket) Did this influence the type of practitioner you chose?

Birth experience:

Who was present at your birth? Who did you want to be present?

Have you ever considered other types of birth than the one you had? (Water birth, home birth, birthing center, hospital, etc)

What type of regulations or restrictions were placed on you because of your location of birth?

During labor did you have multiple birth practitioners?

What ways did you cope with pain during labor and the birth of your child?

Were you able to move around during labor?

Were you separated from your baby right after birth?

Was saving your placenta a priority for you?

Were you shown the placenta?

Other:

If you had another baby what would you change? What options did you wish were available to you?

What were your expectations about birth beforehand and how did they change after you had your baby?

If you have given birth multiple times did you use the same provider? Why, why not?

Did you breastfeed? Was that a priority for you? When did you begin and end breastfeeding?

How do you feel about the birthing options available to women in the Louisville area?

Word association with OB/GYN, Midwife and Doula. 
APPENDIX C: STUDY FLYER

UofL Institutional Review Boards

IRB NUMBER: 16.0971

IRB APPROVAL DATE: 01/26/2017

\section{You're Invited: Birth Experience Study}

\section{Take a short survey to share your birth experiences and opinions!}

Take a brief online survey that will last no more than 10 minutes. If interested, please consider scheduling a $30 \mathrm{~min}$ to 1 -hour interview in person. No followup or long-term commitment is necessary.

After learning about the high maternal mortality rate in the USA, compared to the rest of the developed world, I became interested in finding the reasons our country has fallen behind. This developed into my Senior Honors Thesis, which attempts to understand the reasons why specific types of birthing practitioners are used in childbirth. I am looking forward to hearing your impressions, opinions and experiences during the birth of your child/children and would be happy for any time you may be willing to give!

In order to be eligible to participate, you must be between 18-65 years of age, not currently pregnant and have given birth one or more times in your life.

There are no direct benefits to participating in this study, however this research will be published in the University of Louisville Senior Honors Thesis online archives and may be a useful tool to future women looking to learn more about birthing options. No names or identifying information will be published.

You can take the survey right now!

Access the survey by going to https://goo.gl/forms/1g4W1ukg9u1LLRrO2 . For more information you may also email birthsurvey2017@gmail.com

For more information please contact the study investigators:

Alice Darling ajdarl01@louisville.edu

Dr. Christopher Tillquist

Department of Anthropology

242 Lutz Hall

Belknap Campus

University of Louisville

Louisville, KY 40292

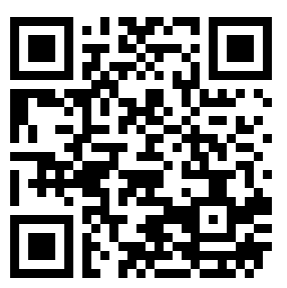

Scan this with your smartphone camera using SnapChat or a QR code scanning app to view the survey online! 


\section{APPENDIX D: OSEA STATEMENT ON HUMAN SUBJECTS REVIEW/INSTITUTIONAL REVIEW BOARD}

The Open School of Ethnography and Anthropology is an independent non-degree school that provides courses at the undergraduate and graduate level. OSEA does not receive federal support for its programs. Nonetheless, OSEA requires that all students in research practicum programs learn about Human Subjects Review (HSR) issues, research ethics, and Institutional Review Board (IRB) processes. This information is imparted in OSEA research methods and practicum courses.

As part of its educational program, OSEA has adopted and modified appropriately as its Human Subjects Review guidelines, the Indiana University statement on the exemption of student research from IRB/HSR (See below for pertinent passages from the statement and a link to the full statement on the IU website).

As is commonly held by a majority of institutions of higher education, research conducted within the context of regularly assigned coursework is considered eligible for exemption from HSR/IRB. Furthermore such research is considered to be exempt if the research methods are (a) not invasive, intrusive or stressful in terms of either physical or psychological criteria; (b) do not involve vulnerable populations at risk; and (c) do not have the potential for placing either the student researcher or the subjects of research at more than a normal level of everyday risk that is common for even those who are not involved in the research process but share the same social and experiential contexts.

\section{ELIGIBILITY FOR EXEMPTION:}

OSEA educational experiences are based in seminar, workshop, forum, or practicum coursework. Any and all research conducted by students in any OSEA program is realized for the explicit purpose of student training. Practicum training exercises, including independent student research projects, are not considered research that leads to generalizable knowledge. As such projects conducted in OSEA programs are categorically considered to be eligible for exemption from HSR/IRB. COMPLIANCE WITH EXEMPTION:

- OSEA staff and faculty expressly exclude and prohibit any student or participant in any OSEA program to: (a) use physically or psychologically intrusive, invasive, harmful, deceitful, or stressful methods or research protocols; (b) conduct research with vulnerable populations at risk; and (c) conduct research in any situation or under any circumstances that involve any risk which is more than, or beyond, the normal, everyday, minimal potential of routine experience in the socio-cultural settings and contexts of the OSEA programs. The OSEA faculty, including teaching and research staff, are involved in the evaluation of all student conducted research and determine whether or not a project is in compliance with the ethical and human subjects guidelines established by OSEA.

- The research methodologies that student use in their practicum exercises are limited to nonintrusive methods and protocols, such as interviewing, observation, participation, focus group, structured questionnaires, surveys, elicitation of narratives, audio-visual, audio and photographic recordings, and study of publicly available documents and archival materials. Protocols involving biomedical, genetic, human tissue, or deception are prohibited by OSEA.

Research subjects are limited to consenting adults who are required to be informed of the risks involved in their participation in the student conducted research practicum. In the case of 
minors their consent must attained as well as the consent of their parents or guardians and must be restricted to issues of learning, use, acquisition, and expression of linguistic or cultural competencies within settings that include the approval and or supervision of parents or guardians. The regulated process of attaining consent from all participants is separately provided and includes the routine provision for the maintenance of subject anonymity although informed consent also grants all subjects their choice to reveal their identity.

- All research materials created, collected or produced by student participants are to be kept in the institutional archives OSEA. These materials are organized by the student or participant who submits materials in original and/or copy format using standardized procedures for the maintenance of anonymity in those cases where subjects have made this request.

- In those cases in which a student participant does not comply with the ethical codes and standards of ethnographic research and of cultural anthropology as established by the American Anthropological Association or with the ethical standards and Human Subjects Review Guidelines established by OSEA, the student or participant will be immediately expelled from the program at the discretion of the Director and OSEA Staff without any further discussion and without any further obligation or responsibility on the part of OSEA or any of its institutional partners, including economic compensation for financial losses, reimbursement of fees, or legal repercussions. 